\title{
Factors responsible for increased percent recirculation in arterio-venous fistula among the haemodialysis patients
}

\author{
Mahbub $\mathrm{T}^{1}$, Chowdhury MNU ${ }^{1}$, Jahan $\mathrm{F}^{2}$, Islam $\mathrm{MN}^{1}$, Khan $\mathrm{FM}^{1}$, Sikder $\mathrm{NH}^{3}$, Rahman $\mathrm{M}^{4}$ \\ ${ }^{1}$ Department of Nephrology, Dhaka Medical College Hospital, Dhaka, ${ }^{2}$ Bangabandhu Sheikh Mujib \\ Medical University (BSMMU), Dhaka, ${ }^{3}$ Northern International Medical College, Dhaka, ${ }^{4}$ Department \\ of Haematology, BSMMU, Dhaka. Email: taniaimran1@yahoo.com
}

\begin{abstract}
Recirculation is an important issue in haemodialysis (HD) patients as increased percent recirculation causes decreased dialysis delivery of the patients. The purpose of the study was to determine the amount and factors of recirculation in those patients. The study was a cross sectional one carried in the department of Nephrology, Dhaka Medical College and Hospital during October 2010 to September 2011. A total of 118 end stage renal disease patients with arterio-venous fistula who were on HD for more than 3 months were purposively selected. The degree of recirculation was measured with urea based two needle technique method. For each patient distances between arterial and venous and distances of needles from fistula and its directions were recorded. Echocardiography and A-V fistula Colour Doppler Ultrasound were also performed. The mean A-V fistula recirculation was $8.1 \pm 5.5 \%$ with a range $0-66 \%$. The most common factors were close proximity and improper arterial and venous needles placement. No difference was observed between diabetic and non diabetic also between hypertensive and normotensive. A-V fistula recirculation is common occurrence in HD patients and the most common factors of recirculation are misplacement and close proximity of needles therefore emphasis should be given on education and training of HD staffs.
\end{abstract}

\section{Introduction}

End stage renal disease (ESRD) is one of most common life threatening diseases and the number of ESRD patients are expanding. Therefore the number of Haemodialysis(HD) patients are also increasing rapidly ${ }^{1}$.World wide HD is method of renal replacement therapy for majority of ESRD patients and survival of haemodialysis patients is an important and very well discussed issue., ${ }^{2}$ Though the life expectancy of patients with ESRD has improved a lot after the introduction of dialysis but unfortunately still it is far below that of the general population. A study from Iran observed that one, three, and five-year survival of ESRD patients on HD is $89.2 \%, 69.2 \%$, and $46.8 \%$, respectively ${ }^{3}$. Another study observed that the mean life span at age 49 in the United States is 33 years in the general population but it was only approximately 7 years in patients receiving maintenance dialysis ${ }^{4}$.So more emphasis should be given for adequate dialysis. Different factors affect in the survival of ESRD patients, one of the important factors is inadequate dialysis $^{5,6,7}$. It was well established that recirculation is one of the important causes of inadequate dialysis. Recirculation is defined as the volume of blood that has crossed the dialyzer and is recirculated directly through the extracorporeal circuit again rather than returning to the systemic circulation. There by it cuts down the efficiency of dialysis. ${ }^{8}$ Many factors are responsible for recirculation especially low blood flow through fistula, low left ventricular ejection fraction ,Stenosis in vessels and improper arterial and venous needle placement and close proximity between needles and can be prevented by appropriate measures. ${ }^{9,10,13}$ Another importance of recirculation study is to early detection of access dysfunction especially to predict the presence of venous stenosis and low blood flow through fiatula. ${ }^{12}$ According to NFK-DOQI guideline any recirculation more than $10 \%$ by two needle urea based method and more than $5 \%$ by ultrasound dilution method should be investigated by further extensive investigation to identify the cause. ${ }^{11}$ Thus screening for recirculation is an important issue in HD patients.

Due to scarcity of donor, HD is the choice of treatment in majority of patient with ESRD in our community and the treatment cost of HD is very high, especially for our poor people. More over each year Government has to take an extra burden 
to serve this group of patients and the demand is also increasing day by day. So we should be more careful in dealing with this group of patients and ensure adequate dialysis delivery in each session to minimize our economic burden. The measurement of A-V fistula recirculation in Haemodialysis is an important cause of inadequate dialysis as well as an indicator of access dysfunction. ${ }^{10,11}$ Therefore by detecting the amount of recirculation and causes responsible it we can improve the quality of dialysis delivery to our patients. Considering recirculation as an important issue in haemodialysis and as there was no similar such study in Bangladesh, this study was directed to estimation of recirculation among our haemodialysis patients as a baseline work to improve dialysis delivery in future as well as this work will create a ground for future extensive study.

\section{Materials and Methods}

Objectives: Different study show that haemodialysis access recirculation is a common occurrence and is a preventable factor for underdialysis. Thereby the study was directed to estimation of recirculation among haemodialysis patients as well as to identify the factors responsible for it.

Sample Size: We considered every available ESRD patient on Haemodialysis through A-V fistula at the Department of Nephrology, Dhaka Medical College Hospital. There was no past record of similar study in Bangladesh, we followed a study done by Abdollahi et $\mathrm{al}^{16}$ as reference. With this the sample size was determined by following formula:

$$
\begin{gathered}
Z^{2} p q \\
=----- \\
d^{2} \\
=196 .
\end{gathered}
$$

$[Z=1.96$, the critical value of $\mathrm{z}$ at $95 \%$ level of significance. $\mathrm{P}=0.15$ (Considering the prevalence of recirculation 15\%) (Abdollahi et al. 2010)

$\mathrm{q}=1-\mathrm{p}=0.85$

$\mathrm{d}=0.05$ margin of error]

Therefore, $\mathrm{n}=196$ (Sample size).

Total 118 patients were included as per selection criterion.

Sampling Method: Sampling was done by purposive sampling. Inclusion criteria were Patients undergoing haemodialysis by arterio venous fistula for more than three months, More than 18 years and those who gave consent. Exclusion criteria, patients undergoing haemodialysis by temporary access or permanent catheter was excluded.

Subjects and Methods/methodology: This was a Cross sectional study from October 2010 to
September 2011 Conducted on ESRD patients in Dept of Nephrology, Dhaka Medical college and Hospital. HD was performed for 4 hours, two to three times per week, using triacetate hollow fiber dialyzer Nipro SUREFLUX-130N, Japan with HD machine Fresenius medical care type 4008B, Germany with bicarbonate-based dialysate at a delivered bicarbonate concentration of $35 \mathrm{~m} \mathrm{Eq} / \mathrm{L}$. Blood flow was maintained at $250-350 \mathrm{ml} / \mathrm{min}$ and the dialysate flow rate at $500 \mathrm{ml} / \mathrm{min}$. A standardized questionnaire was used to collect demographic data, cause of ESRD, the date of HD onset, the type of access for HD, the date of creation and use of A$\mathrm{V}$ fistula. The degree of recirculation was measured with Urea based two needle method from the following formula: Percent recirculation $=([\mathrm{P}-\mathrm{A}] \div$ $[\mathrm{P}-\mathrm{V}]) \times 100$. Where $\mathrm{P}, \mathrm{A}$, and $\mathrm{V}$ refer to the urea concentrations in the peripheral blood, predialyzer arterial line, and postdialyzer venous circuit, respectively. The following protocol was used for blood sampling.The ultrafiltration was turned off approximately 30 minutes after the initiation of HD and then arterial and venous line samples were obtained. Access blood flow was reduced to 50 $\mathrm{mL} / \mathrm{min}$ and 15 to 30 seconds later, the systemic blood sample from the arterial blood line was obtained $^{13}$. The measurements of all blood samples were done in single laboratory. The patients were divided into three groups: group 1 patients 0$.9 \%$ [most well functioning fistula] recirculation and group II patients with recirculation 1-10\% [Within acceptable limit]. Group III $>10 \%$ recirculation. [Above the acceptable limit of recirculation]. For each patient distances between arterial and venous needles and distances of needles from A-V fistula and its directions was recorded. Echocardiography and A-V fistula Color Doppler Ultrasound were also performed. The findings were analyzed by SPSS statistical program. Chi square test or Fisher Exact test were used for qualitative data. For quantitative data, the were compared by using ANOVA test. Association between risk factors and recirculation rate was evaluated by $\mathrm{COX}$ regression model. Statistical significance was assessed at the 0.05 probability level in all analyses.

\section{Results}

Maximum of the patients were found in three groups between 41-50 years. In this current study it was observed that the age range varied from 18 to 75 years in whole study patients and majority of the patients were found in the $5^{\text {th }}$ decade, which was $52.4 \%$ in group I, $30.1 \%$ in group II and $42.9 \%$ in group III. The mean age was $43.81 \pm 11.95$ years in group I, 43.58 \pm 12.89 years in group II and $44.36 \pm 11.45$ years in group III. Age difference was not stastially significant ( $\mathrm{p}>0.05)$. 
Male were 92 and female 26 with a male female ratio 2.5:1.male was found $85.7 \%$ in group I, $80.7 \%$ in group II and $40.0 \%$ in group III. Male was significant higher in group I and group II. Female were predominant in group III. The difference was statistically significant $(\mathrm{p}<0.023)$.

Among the cause of ESRD, DM was found $9(42.9 \%)$ in group I, 39(47.0\%) in group II and $4(28.6 \%)$ in group III. GN was found $7(33.3 \%)$ in group I, $25(30.1 \%)$ in group II and $3(21.4 \%)$ in group III. Hypertension was found $4(19.0 \%)$ in group I, 3(3.6\%) in group II and 2(14.3\%) in group III. ADPKD and obstructive nephropathy was not found in group I, 3(3.6\%) in group II and 2(14.3\%) in group III. In group I, group II and group III, $1(4.8 \%), 10(12.0 \%)$ and $1(7.1 \%)$ were unknown etiology. There difference was not statistically significant $(p>0.05)$ among three groups in chi square test.

Radiocephalic was found $19(90.5 \%)$ in group I, $66(79.5 \%)$ in group II and $9(64.3 \%)$ in group III. Brachiocephalic was found $2(9.5 \%)$ in group I, $17(20.5 \%)$ in group II and $5(35.7 \%) \mathrm{n}$ group III. The difference was not statistically significant $(p>0.05)$ among the three groups in chi square test.

Table I shows, the mean percent recirculation of study patients. Mean recirculation was found $0.09 \pm 0.27 \%$ with range from 0 to $0.9 \%$ in group I, $4.15 \pm 2.56 \%$ with range from 1 to $9 \%$ in group II, $21.29 \pm 15.07 \%$ with range from 11 to $66 \%$ in group III and mean recirculation $8.1 \pm 5.5 \%$ with range from 0 to $66 \%$ in the whole study patients. The differences was statistically significant $(p<0.001)$ between three groups in ANOVA test.

Table II shows, distribution of improper arterial and venous needle placement in study patients. Improper needle placements were not found $21(100.0 \%)$ in group I, $78(94.0 \%)$ in group II and $4(28.6 \%)$ in group III. In approved direction was found $5(6.0 \%)$ and $10(71.4 \%)$ in group II and group III respectively but not found in group I. The differences was statistically significant $(\mathrm{p}<0.001)$ among the three groups in chi square test.

Table III shows distribution of distance between arterial and venous in study patients. A distance less than $4 \mathrm{~cm}$ was found $2(9.5 \%)$ in group I, $31(37.3 \%)$ group II and $7(50 \%)$ in group III. The mean distance between arterial and venous needle was found $6.28 \pm 2.1 \mathrm{~cm}$ with range from 4.2 to 8 $\mathrm{cm}$ in group I, $4.6 \pm 2.65 \mathrm{~cm}$ and 2.5 to $14 \mathrm{~cm}$ in group II and $2.5 \pm 1.25 \mathrm{~cm}$ with range from 2.4 to $13.0 \mathrm{~cm}$ in group III. The difference was statistically significant $(p<0.03)$ among the three groups in ANOVA test.
Table IV shows the distribution of ejection fraction in study patients. Ejection Fraction were found $61.52 \pm 5.17 \%$ with range from 51 to $72 \%$ in group I, $57.28 \pm 6.95 \%$ with range from 40 to $70 \%$ in group II and $52.71 \pm 4.95 \%$ with range from 35 to $60 \%$ in group III. Ejection fraction also had significant negative correlation with recirculation. $(r=0.250 ; p<0.001)$. The difference was statistically significant $(\mathrm{p}<0.001)$ among the three groups in ANOVA test.

Table $\mathrm{V}$ shows the distribution of the mean blood flow through the fistula in study patients. Blood flow were found $1330.9 \pm 622.4 \mathrm{ml} / \mathrm{min}$ with range from 677.25 to $2279 \mathrm{ml} / \mathrm{min}$ in group I, $1174.1 \pm 554.8 \mathrm{ml} / \mathrm{min}$ with range from 456 to 2893 $\mathrm{ml} / \mathrm{min}$ in group II and $1073.3 \pm 363.4 \mathrm{ml} / \mathrm{min}$ with range from 475 to $1571 \mathrm{ml} / \mathrm{min}$ in group III. Though the difference were not statistically significant $(\mathrm{p}>0.05)$ among the groups, there was significant negative correlation $(r=0.201 ; \mathrm{p}<0.046)$ was observed between the two variables. The study patients had no stenosis in fistula.

The mean duration of fistula was found $7.71 \pm 5.81$ months with range from 3 to 36 months in group I, $9.89 \pm 6.48$ months with range from 5 to 24 months in group II and $6.81 \pm 5.18$ months with range from 3 to 27 months in group III. The mean difference was not statistically significant $(\mathrm{p}>0.05)$ among the three groups in ANOVA test. The interval between fistula constriction and first needling of the study patients. The mean interval between fistula construction and first needling was found $51.17 \pm 35.92$ days with range from 27 to 150 days in group I, 40.62 \pm 35.36 days ranging from 21 to 210 days in group II and $29.5 \pm 2.36$ days ranging from 21 to 33 days in group III. The difference was not statistically significant $(p>0.05)$ among the three groups in ANOVA test

Table I: The percent recirculation of the study patients $(\mathrm{n}=118)$

\begin{tabular}{|c|c|c|c|c|c|}
\hline & Total & $\begin{array}{l}\text { Group I } \\
(n=21)\end{array}$ & $\begin{array}{l}\text { Group II } \\
(n=83)\end{array}$ & $\begin{array}{c}\text { Group III } \\
(n=14)\end{array}$ & _ $P$ value \\
\hline & Mean $\pm S D$ & Mean \pm SD & Mean \pm SD & Mean \pm SD & \\
\hline $\begin{array}{l}\text { Percent of } \\
\text { recirculation (\%) }\end{array}$ & $8.1 \pm 5.5$ & $0.09 \pm 0.27$ & $4.15 \pm 2.56$ & $21.29 \pm 15.07$ & $0.001^{\mathrm{s}}$ \\
\hline Range(min-max) & $(0-66)$ & $(0-0.9)$ & $(1-9)$ & $(11-66)$ & \\
\hline
\end{tabular}

Table II: Distribution of the study patients according to Improper arterial \& venous needle placement $(\mathrm{n}=118)$.

\begin{tabular}{llllllll}
\hline $\begin{array}{l}\text { Improper arterial \& } \\
\text { venous needle placement }\end{array}$ & $\begin{array}{l}\text { Group I } \\
(\mathrm{n}=21)\end{array}$ & $\begin{array}{l}\text { Group II } \\
(\mathrm{n}=83)\end{array}$ & $\begin{array}{l}\text { Group III } \\
(\mathrm{n}=14)\end{array}$ & $\begin{array}{c}\mathrm{P} \\
\text { value }\end{array}$ \\
\cline { 2 - 6 } & $\mathrm{N}$ & $\%$ & $\mathrm{~N}$ & $\%$ & $\mathrm{n}$ & $\%$ & \\
\hline Absent & 21 & 100.0 & 78 & 94.0 & 4 & 28.6 & $0.001^{\mathrm{s}}$ \\
Present & 0 & 0.0 & 5 & 6.0 & 10 & 71.4 & \\
\hline
\end{tabular}


Table III: Mean distance between arterial and venous needle of the study patients $(\mathrm{n}=118)$

\begin{tabular}{|c|c|c|c|c|c|c|c|}
\hline \multirow[t]{2}{*}{$\begin{array}{l}\text { Distance between } \\
\text { arterial and venous } \\
\text { needle (in } \mathrm{cm} \text { ) }\end{array}$} & \multicolumn{2}{|c|}{$\begin{array}{l}\text { Group I } \\
(n=21)\end{array}$} & \multicolumn{2}{|c|}{$\begin{array}{c}\text { Group II } \\
(\mathrm{n}=83)\end{array}$} & \multicolumn{2}{|c|}{$\begin{array}{c}\text { Group III } \\
(\mathrm{n}=14)\end{array}$} & \multirow[t]{2}{*}{$P$ value } \\
\hline & $\mathrm{N}$ & $\%$ & $\mathrm{n}$ & $\%$ & $\mathrm{n}$ & $\%$ & \\
\hline$\overline{<4}$ & 2 & 9.5 & 31 & 37.3 & 7 & 50 & \\
\hline$\geq 4$ & 19 & 90.5 & 52 & 62.7 & 7 & 50 & \\
\hline $\begin{array}{l}\text { Mean } \pm \text { SD } \\
\text { Range (min-max) }\end{array}$ & \multicolumn{2}{|c|}{$6.28 \pm 2.1$} & \multicolumn{2}{|c|}{$\begin{array}{l}4.6 \pm 2.65 \\
(2.5-14)\end{array}$} & \multicolumn{2}{|c|}{$\begin{array}{l}2.5 \pm 1.25 \\
(2.4-13)\end{array}$} & 0.037 \\
\hline
\end{tabular}

Table IV: The mean left ventricular ejection fraction distribution of the study patients $(\mathrm{n}=118)$

\begin{tabular}{cccc}
\hline $\begin{array}{c}\text { Group I } \\
(\mathrm{n}=21)\end{array}$ & $\begin{array}{c}\text { Group II } \\
(\mathrm{n}=83)\end{array}$ & $\begin{array}{c}\text { Group III } \\
(\mathrm{n}=14)\end{array}$ & $\begin{array}{c}\mathrm{P} \\
\text { value }\end{array}$ \\
\cline { 2 - 4 } Mean $\pm \mathrm{SD}$ & Mean $\pm \mathrm{SD}$ & Mean $\pm \mathrm{SD}$ & \\
\hline
\end{tabular}

Ejection fraction $\left(\%, 61.52 \pm 5.17 \quad 57.28 \pm 6.95 \quad 52.71 \pm 4.95 \quad 0.001^{\text {s }}\right.$

$\begin{array}{lllll}\text { Range (min-max }) & (51-72) & (40-70) & (35-60) & 0.001^{s}\end{array}$

Table V: The mean blood flow through the fistula of the study patients $(\mathrm{n}=118)$

\begin{tabular}{|c|c|c|c|c|}
\hline & $\begin{array}{l}\text { Group I } \\
(n=21)\end{array}$ & $\begin{array}{c}\text { Group II } \\
(\mathrm{n}=83)\end{array}$ & $\begin{array}{c}\text { Group III } \\
(n=14)\end{array}$ & \multirow[t]{2}{*}{$\mathrm{P}$ value } \\
\hline & Mean \pm SD & Mean \pm SD & Mean \pm SD & \\
\hline $\begin{array}{l}\text { Blood flow through } \\
\text { the fistula }(\mathrm{ml} / \mathrm{min})\end{array}$ & $1330.9 \pm 622.4$ & $1174.1 \pm 554$ & $1073.3 \pm 363.4$ & \multirow[t]{2}{*}{$0.526^{\mathrm{ns}}$} \\
\hline Range & $(677.5-2279)$ & $(456-2893)$ & $(475-1571)$ & \\
\hline
\end{tabular}

\section{Discussion}

In this current study it was observed that $82.2 \%$ patients had recirculation, which is consistent with Salami et al, where the investigators showed $80.4 \%$ had patient had recirculation ${ }^{14}$. On the other hand, Beladi Mousavi et al ${ }^{13}$ showed $17.0 \%$ and Abdollahi et al ${ }^{16}$ found $15.0 \%$, which may be due to their health professional are well trained as well as their availability of modern facilities in their hospital. The present study findings were discussed and compared with previously published relevant studies.

Recirculation was not age dependent according to this study. Similarly, Beladi Mousavi et al ${ }^{13}$ showed almost similar age range in their study patients, where the authors found the age range was 16 to 75 years. On the other hand, Abdollahi et al ${ }^{16}$ has observed higher mean age in their study patients, which was $50.93 \pm 17.23$ years in comparision to us. This increase mean age may be due to increase life expectancy by improved quality of dialysis. Moreover due to financial burden our patient could not afford more than two session of dialysis per week rather than required three sessions. This reduced dose of dialysis affect the overall survival rate in HD patients ${ }^{9}$.

Male was more common in the whole study subjects, the male female ratio was 2.5:1. Male was significant higher in group I and group II. Similarly, Beladi Mousavi et al ${ }^{13}$ found overall, $58.69 \%$ and $41.30 \%$ patients were male and female respectively, which support the current study. This discrepancy among male female ratio occurred probably due to the fact that males are most privileged than females in the society to receive advanced medical facilities. females and diabetics have relative low blood flow through fistula than their male counterpart. ${ }^{11}$ The increased amount of recirculation in females may be due to relative low blood flow through fistula .

Regarding the cause of ESRD it was observed in this current study that DM and GN were the more frequent in all three groups According to Beladi Mousavi et al ${ }^{13}$ recirculation does not vary among diabetic and non diabetic and also hypertensive and normotensive. In another study Salimi et al. ${ }^{14}$ mentioned in their study that history of hypertension and diabetes mellitus were not significantly correlated with recirculation, which are comparable with the current study.

Majority of the patients had radiocephalic which were $90.5 \%$, which was not significant $(p>0.05)$. Similar findings obtained by Salimi et $\mathrm{al}^{14}$.

In this current series it was observe that the mean percent recirculation was $8.1 \pm 5.5 \%$ with range from 0 to $66 \%$ in the whole study patients. range from 11 to $66 \%$, which was significantly higher in group III. Similarly, Vanstone et al ${ }^{17}$, Salimi et al $^{14}$ and Rafique et $\mathrm{al}^{15}$ found the mean percent recirculation were $6.4 \%, 8.75 \%$ and $9.55 \pm 5.5 \%$ respectively, which are closely resembled with the current study.

Among the causes, improper arterial \& venous needle placement significantly associated with increase recirculation, Similarly, a significant $(p<0.001)$ association between recirculation and improper arterial and venous needle placement was also seen by Beladi Mousave et al ${ }^{13}$. Similar significant association also observed by Abdollahi et $\mathrm{al}^{16}$, Salimi et $\mathrm{al}^{14}$.

The study revealed that the mean distance between arterial and venous needle was significantly $(p<0.05)$ decline with increased percent recirculation.

In the current study the left ventricular ejection fraction was 35 to $60 \%$. significantly $(\mathrm{p}<0.05)$ decline of LVEF occur with increased recirculation. Beladi Mousavi et al ${ }^{13}$ on their study on patients having heart failure and showed that the average LVEF in without recirculation was $46.76 \pm$ 
$5.57 \%$ and with recirculation was $32.67 \pm 7.52$, which also significantly $(\mathrm{p}=0.002)$ associated with recirculation, which is consistent with the current study.

In this present study it was observed that the mean blood flow through the fistula was found $1330.9 \pm 622.4 \mathrm{ml} / \mathrm{min}$.In current study blood flow decline with increased percent recirculation $(\mathrm{r}=0.201)$ but the difference was not significant ( $>0.05$ ). Similarly, Beladi Mousavi et al ${ }^{13}$ showed the mean $\mathrm{A}-\mathrm{V}$ fistula flow rate in both groups was more than $400 \mathrm{ml} / \mathrm{min}$ in without recirculation group $1229.41 \pm 753.96 \mathrm{mill} / \mathrm{min}$ and with recirculation, $653.33 \pm 209.98 \mathrm{mill} / \mathrm{min}$ ) and the mean A-V fistula flow rate was significantly higher in without recirculation $(\mathrm{p}=0.001)$, which is consistent with the current study.

In this present series it was observed that all patients had no stenosis in fistula, which is consistent with the study done by Beladi Mousavi et al ${ }^{13}$.Probably because of the fact that recirculation is a late indicator of Stenosis and almost $>50 \%$ Stenosis is required for recirculation. ${ }^{11} \mathrm{We}$ could not found any association between the two variables as fortunately we did not find any patient with stenosis and obstruction.

The mean difference of duration of fistula used was not statistically significant ( $p>0.05)$ among the three groups. There was no correlation $r=0.123$; $(p=0.186)$ was found between recirculation with duration of fistula. Similarly, Salimi et $\mathrm{al}^{14}$ also found no significant $(p>0.05)$ association between recirculation with duration of fistula, which support the current study. However, Beladi Mousavi et $\mathrm{al}^{13}$ showed the length of time of A-V fistula use was $26.59 \pm 9.37$ months in without recirculation and $33.20 \pm 7.35$ months in with recirculation group. There also was a significant association $(\mathrm{p}=0.001)$. In our study we could not find the relationship between duration of fistula use and recirculation. As stated before In our country due to cost strain majority of the patients receive inadequate dose of $\mathrm{HD}$ rather than required total 12 hours dialysis per week that affect on their net survival thereby indirectly they have reduced duration of fistula use in comparison to others due to inadequate dialysis. Probably to establish such relationship we need a study group with prolong duration of fistula use.

In this current study it was observed that the interval between fistula construction and first needling was not associated with recirculation $(\mathrm{p}=0.137)$. Beladi Mousavi et $\mathrm{al}^{13}$ observed in their study that the average time between creation and use of $\mathrm{A}-\mathrm{V}$ fistula in without recirculation and with recirculation were $90 \pm 22$ days and $40 \pm 15$ days respectively. In our study we could not get the relationship cause most of the patients denied to create their fistula in stage VI of CKD and majority of them created it when they were in emergency phase of dialysis and receiving dialysis through catheter. That is they usually don't give enough time for fistula maturation after creation of AV fistula. As catheters are not suitable for dialysis for prolong period due to its complications. A newly created fistula needs almost 4 to 6 weeks for maturation ${ }^{8}$. Thereby we could not get this relationship between this two variable from this study.

Conclusion: In this observational study recirculation was a common findings but according to this study it does not dependent on age, type of fistula, cause of ESRD, but more frequent in female. Improper arterial and venous needle placement and close proximity between needles were identified as most important causes of recirculation. Left ventricular ejection fraction had significant association with recirculation. A negative correlation was observed between blood flow and recirculation. Senosis and obstruction in fistula was not to be a contributing factor in present study. No association was observed between recirculation and duration of fistula use and wait after fistula creation.

Limitation: The study was conducted over a short period and included only one centre which may not represent whole dialysis population. Stenosis was not excluded as gold standard method to detect stenosis is venography.

Recommendation: A large multicenter study is demanded to verify the existence of such high percentage of recirculation found in the present study, to evaluate the risk factors associated with recirculation found in this study as well as other risk factors ascertain in large study group. Specific training program dedicated to dialysis care personnel should be launched nationwide to adopt attitude which can eliminate this correctable cause of inadequate dialysis.

\section{References}

1. USRDS: The United States Renal Data System: Overall hospitalization and mortality. Am J Kidney Dis 2003; 42 (6): 136-40.

2. USRDS: The United States Renal Data System. Excerpts from the USRDS 2008 annual data report: Atlas of end-stage renal disease in the United States. Am J Kidney Dis 2009; 1(1): 1. 
3. Beladi Musabi SS, Hayati F, Alemzadeh Ansari MJ. Survival at 1,3 , and 5 Years in Diabetic and Nondiabetic Hemodialysis Patients. IJKD 2010; 4: 74-7.

4. Mailloux LU, Bellucci AG, Napolitano B. Survival estimates for 683 patients starting dialysis from 1970 through 1989: Identification of risk factors for survival. Clin Nephrol 1994; 42: 127.

5. Murphy SW, Foley RN, Barrett BJ. Comparative mortality of hemodialysis and peritoneal dialysis in Canada. Kidney Int 2000; 57: 1720-6.

6. Goodkin, DA, Bragg-Gresham, JL, Koenig, KG, Wolfe, RA. Association of comorbid conditions and mortality in hemodialysis patients in Europe, Japan, and the United States: the Dialysis Outcomes and Practice Patterns Study (DOPPS). J Am Soc Nephrol 2003, 14: 3270.

7. Miskulin, DC, Meyer, KB, Martin, AA. Comorbidity and its change predict survival in incident dialysis patients. Am J Kidney Dis 2003; 41: 149.

8. Kumar, V., Depnerm, T., Besarb, A., and Ananthakrishnan, S. Arterio venous access for hemodialysis. Hand book of dialysis. 2001; 314-21.

9. Depner TA,Dialysis therapy.Lippincott Willioms and Wilkins, Text book of Nephrology 2001;84:1486-9.

10. Sherman, R.A.. The measurement of dialysis access recirculation. Am J Kidney Dis. 1993; 22(4): 616-21.
11. Whittier WL. Surveillance of Hemodialysis Vascular Access. Semin Interval Radiol. 2009; 26(2): 130-138.

12. Alloatti, S., Magnasco, A., Manes, M., Bonfant, G. Hemodialysis access. G Ital Nefrol. 2004; 21(5): 43845.

13. Beladi Musabi SS ,Tavazoe M,Hayati F,Sametzadeh M.Arterio-Venous Fistula Recirculation in Haemodialysis: Causes and Prevalences.Shiraz E Medical Jour 2010; 11: 10-14.

14. Salimi J, Razeghi E, Karijaliam H, Meysamie A, Dahhaz M, Dadmehr M. Predicting Hemodialysis Access Failure with the Measurement of Dialysis Access Recirculation. Original article 2008; 19(5): 781-784.

15. Rafique Z, Abbas G, Shafi T. Comparison of arteriovenous fistula recirculation by thermodilution and urea - based method. J Coll Physicians Surg Pak. 2007; 17(10): 603-6.

16. Abdollahi A, Shariati A, and Bakhsh RT. Arteriovenous Fistula Recirculation and its Relationship with Some Factors in Hemodialysis Patients. Jgbfnm. 2010; 7(2): 15-22.

17. Van Stone JC. Peripheral venous blood is not the appropriate specimen to determine the amount of recirculation d uring hemodialysis. ASAIO J. 1996; 42(1): 41-5. 